Aletria, Belo Horizonte, v. 30, n. 1, p. 95-116, 2020

(c) (1)

\title{
Repetição, diferença, reescritura: das vantagens do "entre"
}

\section{Repetition, Difference, Rewriting: The Advantages of "In-Betweenness"}

\author{
Maurício Hoelz \\ Universidade Federal Rural do Rio de Janeiro (UFRRJ), Seropédica, Rio de Janeiro \\ / Brasil \\ mauriciohoelz@gmail.com \\ http://orcid.org/0000-0002-1392-0645

\section{Andre Bittencourt} \\ Universidade Federal Rural do Rio de Janeiro (UFRRJ), Seropédica, Rio de Janeiro \\ / Brasil \\ andrevbitt@gmail.com \\ http://orcid.org/0000-0001-5211-0250
}

Resumo: O artigo pretende situar o conceito pioneiro e seminal de "entre-lugar" formulado por Silviano Santiago no início da década de 1970 dentro de um conjunto de discussões do que poderíamos chamar de um "primeiro momento" do debate acadêmico pós-colonial. Para isso, indicaremos aproximações com ideias contemporâneas de dois outros críticos culturais de origem colonial que se estabeleceram e se consagraram no circuito acadêmico hegemônico, Edward Said e Homi K. Bhabha. Santiago e Said participaram da recepção imediata das ideias estruturalistas e "pós-estruturalistas" nos Estados Unidos e, por caminhos próximos, mas com alcances teóricos diferentes, perseguiram o questionamento dos padrões europeus de pensamento ao colocar em xeque a ideia de origem. Em momento posterior, Bhabha desenvolverá uma crítica à perspectiva que ele considera binarista de Said, cujos argumentos - sendo este o ponto que gostaríamos de demonstrar-convergem com aqueles já presentes na formulação de Santiago.

Palavras-chave: Silviano Santiago; Edward Said; Homi K. Bhabha; pós-colonialismo; entre-lugar. 


\begin{abstract}
The article attempts to locate the seminal concept of "in-betweenness" formulated by Silviano Santiago in the early 1970s in the awakening of the post-colonial debate. For this purpose, it approaches contemporary ideas of two cultural critics with colonial origins - Edward Said and Homi K. Bhabha - which have achieved broad recognition in the hegemonic academic circuit. Santiago and Said both took part in the immediate reception of structuralist and 'post-structuralist' ideas in the United States. Following close paths but with different theoretical achievements, they problematized the European patterns of thought by calling into question the idea of origin. Later in the 1980s Bhabha will criticize what he considers to be the binarism of Said's perspective in terms similar to that already posed by Santiago.
\end{abstract}

Keywords: Silviano Santiago; Edward Said; Homi K. Bhabha; post-colonialism; inbetweenness.

$\mathrm{O}$ artigo pretende situar o conceito pioneiro e seminal de "entrelugar" formulado por Silviano Santiago no início da década de 1970 dentro de um conjunto de discussões do que poderíamos chamar de um "primeiro momento" do debate acadêmico pós-colonial. Para isso, indicaremos aproximações com ideias contemporâneas de dois outros críticos culturais de origem colonial que se estabeleceram e se consagraram no circuito acadêmico hegemônico: Edward Said e Homi K. Bhabha. Santiago e Said participaram da recepção imediata das ideias estruturalistas e "pós-estruturalistas" nos Estados Unidos e por caminhos próximos, mas com alcances teóricos diferentes, perseguiram o questionamento dos padrões europeus de pensamento ao colocar em xeque a ideia de origem. Esse será o nosso ponto de partida. Em momento posterior, Bhabha desenvolverá uma crítica à perspectiva que ele considera binarista de Said cujos argumentos - sendo este o ponto que gostaríamos de demonstrar convergem com aqueles já presentes na formulação de Santiago. A pista mais geral de investigação, a ser explorada em outra oportunidade, é que o influxo dessas ideias "francesas" é mediado e filtrado pelo repertório de questões próprias à condição colonial, especificamente a partir da circunstância latino-americana, no caso de Santiago, o que permite ampliar o sentido dessa teorização.

Em texto introdutório a uma coletânea de trabalhos sobre "as controvérsias do estruturalismo", intitulado "The Space Between" (1971), Eugenio Donato e Richard Macksey (os organizadores do simpósio de 1966 que deu origem ao livro) sugerem que uma fórmula 
de Deleuze sobre Foucault permite contornar a dificuldade de encontrar um denominador comum para as diversas perspectivas em debate: "uma fria e concertada destruição do sujeito, uma vívida aversão a noções de origem, de origem perdida, de origem recuperada [...]" (DELEUZE apud DONATO; MACKSEY, 1972, p. 10, tradução nossa). ${ }^{1}$ Esse prefácio é especialmente interessante porque Donato é não só um dos disseminadores nos Estados Unidos do que posteriormente viria a ser conhecido como "pós-estruturalismo" (que, naquele contexto sincrônico, era visto como uma variante do próprio estruturalismo), mas também um interlocutor tanto de Santiago quanto de Said. Santiago não só dedica o ensaio "O entre-lugar do discurso latino-americano" a Donato como o escreve a seu convite para uma palestra na Université de Montréal. ${ }^{2}$ Já Donato produz uma das primeiras resenhas sobre o segundo livro de Said, Beginnings (1975), confrontando-o com Derrida, e já no prefácio citado acima atribuía importância à recepção crítica de Said do estruturalismo, destacando a necessidade de articular "o espaço vago entre coisas, palavras e ideais" (SAID apud DONATO; MACKSEY, 1972, p. 13, tradução nossa). ${ }^{3}$

Não se trata, obviamente, de proceder aqui a uma crítica das fontes e influências, cujo desmonte é justamente levado a cabo pelos autores que estamos mobilizando. Este estudo é parte de um esforço de testar e incorporar teoricamente o conceito de "entre-lugar" ao campo cognitivo das ciências sociais e à agenda de pesquisa do pensamento social. Ainda que venha sendo objeto de análises relevantes no âmbito das faculdades de Letras, os trabalhos de Silviano Santiago mal começaram a ser explorados pelas ciências sociais. Por sua vez, publicações recentes vêm apontando um déficit - e, ao mesmo tempo, uma fronteira - no pensamento

\footnotetext{
1 "A cold and concerted destruction of the subject, a lively distaste for notions of origin, of lost origin, of recovered origin [...]."

${ }^{2} \mathrm{O}$ ensaio foi escrito originalmente em francês com o título de "L'entre-lieu du discours latino-américain". No entanto, como esclarece Santiago em nota de Uma literatura nos trópicos (1978), Donato teria achado o título enigmático e sugerido outro: "Naissance du sauvage, Anthropophagie Culturelle et la Littérature du Nouveau Monde". A palestra foi lida no dia 18 de março de 1971 e, posteriormente, republicada em inglês, com o título original "The Latin-American Literature: the Space in-between", pela State University of New York at Buffalo (1973). Notemos que o prefácio de Donato e Macksey para o livro The Structuralist Controversy é datado de novembro de 1971.

3 "the vacant spaces between things, words, ideas."
} 
social no Brasil no que diz respeito à necessidade de diálogo com os debates contemporâneos que propõem movimentos de descentramento teórico-críticos do eurocentrismo, tais como as chamadas teorias póscoloniais, decoloniais ou do Sul Global, e a sua inserção em um história transnacional ou global da modernidade em sociedades periféricas (por exemplo, Maia (2011)).

\section{Sobre começos e origens}

Quase dez anos após publicar seu primeiro livro - uma pesquisa sobre Joseph Conrad e a ficção autobiográfica, em 1966 - e logo imediatamente antes da espécie de trilogia composta por Orientalismo (1978), The question of Palestine (1979) e Covering Islam (1981), Said lança Beginnings: Intention and Method (1975), trabalho que trata dos "inícios" literários e seus desdobramentos, sobretudo na literatura modernista ocidental. Diferente do estudo monográfico anterior, que teve por base seu $\mathrm{PhD}$ em Harvard, e das discussões sobre colonialismo que tornaram sua obra incontornável, Beginnings traz de forma central um problema formal e se inscreve explicitamente nos debates da vigorosa crítica cultural francesa dos anos 1960 e 1970, em diálogo com autores como Michel Foucault, Gilles Deleuze, Roland Barthes, Claude Lévi-Strauss e Jacques Derrida. $\mathrm{O}$ argumento geral do livro de Said não é fácil de ser resumido, uma vez que, como ele mesmo aponta na Introdução, os capítulos podem ser lidos de maneira independente e alguns deles foram publicados anteriormente como artigos. De forma ampla, o que o autor propõe é uma "meditação" sobre os variados sentidos implicados na ideia de começos e os diferentes topos que daí decorrem, preocupando-se especialmente com o que significa o impulso (normalmente lido de forma retrospectiva) para começar um projeto literário/intelectual - daí a relevância da discussão sobre a "intenção", que aparece no subtítulo do livro.

Muito da centralidade da categoria "intenção" diz respeito a uma tentativa de Said em recuperar - contra excessos do estruturalismo, por exemplo - a importância de noções como "vontade" (via Nietzsche) e enfatizar a relevância da relação escritor e texto (via Vico). Para ele, autores como Lévi-Strauss ou Barthes teriam "domesticado totalmente em sistemas" a força motriz da vida (SAID, 1985, p. 319). ${ }^{4}$ O "começo"

\footnotetext{
${ }^{4}$ Todas as citações do livro Beginnings (1985), de Edward Said, são tradução nossa.
} 
é precisamente o momento em que essa vontade (que é uma "vontade de poder") se faz presente, mesmo quando o desenrolar do processo não segue aquilo que estava previsto inicialmente. Pelo contrário, todo processo implica, para usar uma citação nietzscheana referendada por Said, "uma ininterrupta cadeia de signos de sempre novas interpretações e ajustes, cujas causas nem precisam estar relacionadas entre si, antes podendo se suceder e substituir de maneira meramente casual" (NIETSZCHE apud SAID, 1985, p. 174-175), o que significa que o desenvolvimento de uma coisa se dá na

sucessão de processos de subjugamento que nela ocorrem, mais ou menos profundos, mais ou menos interdependentes, juntamente com as resistências que a cada vez encontram, as metamorfoses tentadas com o fim de defesa e reação, e também os resultados de ações contrárias bem sucedidas. (NIETSZCHE apud SAID, 1985, p. 174-175). ${ }^{5}$

Nem teleologia, nem sistemas, mas também não aleatoriedade marcam a relação proposta por Said entre o texto e a escritura.

Daí um dos pontos fundamentais de Beginnings, a distinção entre "Origem" (associada por ele também à ideia de Autor) e "começo". Por um lado, como já vimos, a ideia de "começo" é ativa, ao passo que a de origem sugere passividade e é derivativa (X é a origem de Y). A Origem, e, portanto, também a originalidade, remete a uma noção primordial, mítica e divina, portanto estável e segura. Já os começos são necessariamente seculares e humanos, portanto intrinsecamente contingentes e provisórios. Eles também, segundo Said, implicam, sobretudo, retorno e repetição, produzindo diferença a partir do já-familiar (already-familiar) (SAID, 1985, p. 23). A crise da ideia de Origem na modernidade arrasta consigo uma série de consequências, como aquelas estudadas por Foucault em $A s$ palavras e as coisas: a percepção de que uma ordem natural das coisas não mais poderia ser sustentada. Isso traz implicações importantes para o escritor e também para o crítico.

Nesse novo momento, que tem como marco para Said o modernismo, o "escritor consciente" "não pode mais aceitar facilmente

\footnotetext{
${ }^{5}$ Utilizamos a tradução da edição brasileira de Genealogia da moral (1998) feita por Paulo César de Souza.
} 
um lugar numa continuidade que antes se estendia para trás e para frente no tempo" (SAID, 1985, p. 9), ele se sente menos confortável com a ideia de uma precedência e nem sabe mais o que significa se situar em uma linha direta de descendência. Emerge, em suma, de um novo tipo de relação com o cânone. Para ilustrar sua tese, Said recupera novamente Nietzsche, dessa vez em sua polêmica com o filólogo Ulrich von Wilamowitz sobre o "texto clássico". Para este último o texto clássico deveria ser reverenciado, cultivado e emendado como num "sistema de limites e constrangimentos internos" legados por gerações sucessivas (SAID, 1985, p. 9), ao passo que para Nietzsche "era um convite para desvios estranhos do habitual", uma vez que estava inscrito em uma "constelação de forças (instintos, urgências, desejos, vontades)" (SAID, 1985, p. 9). É por não mais se situar em uma tradição "dinástica" que a questão dos "começos", no sentido que vimos anteriormente, torna-se tão importante para o escritor modernista. Ele necessita de iniciativa, ele precisa estabelecer um começo não mais herdado pela tradição:

Os "começos" inauguram outra produção de sentido deliberada - uma gentílica (em oposição a uma sagrada). Ela é "outra" porque, na escrita, essa produção gentílica reivindica um status ao lado de outros trabalhos: é outro trabalho, ao invés de um em linha descendente de $\mathrm{X}$ ou Y. Os começos pretendem fazer essa diferença, eles são sua primeira instância: eles criam um caminho ao lado da estrada. (SAID, 1985, p. 14, grifos do autor).

Por não se situar mais a partir de uma Origem e, portanto, não estar mais inscrito em um mundo marcado por sentidos herdados, o escritor modernista, como nota Hayden White em uma resenha do livro, "ganha seu poder em sua capacidade de deslocar, não apenas a natureza, mas também a cultura (todos os sistemas anteriores de significado)" (WHITE, 1976, p. 10). É nesse contexto que a noção de "in-betweenness" comparece. No livro ela diz respeito à posição do crítico nesse momento. A atitude crítica, seguindo a sugestão de Barthes, deve preocupar-se eminentemente em estudar a "de-formação": "para ler Joyce é preciso de-forma-lo, tanto quanto Joyce de-formava o currículo tradicional" (SAID, 1985, p. 8). O crítico é comparado a um andarilho, que se desloca de um lugar ao outro por seu material, "mas permanece um 
homem essencialmente entre casas" (SAID, 1985, p. 8, grifo do autor). As implicações desse novo lugar podem ser lidas no seguinte trecho:

No processo, o que é retirado de um lugar acaba por violar seu modo habitual de ser: há transposição constante, assim como quando lemos uma imitação de Pound ou Lowell, nós lemos a redistribuição de um original anglo-saxão ou italiano que ocupa um espaço exterior mais amplo, menos bem mapeado e menos previsível do que o original. (SAID, 1985, p. 8).

É nesse sentido também que Said recupera, ao longo do livro, a formulação presente tanto em Deleuze quanto em Vico, da diferença na repetição. Para o primeiro, escreve o autor subscrevendo seu "princípio metodológico", "repetição significa a ausência de uma origem identificável, o que se repete não é o Um, mas o vário, não o mesmo, mas o diferente, não o necessário, mas o aleatório" (SAID, 1985, p. 377-378). Said concebe, então, com a ajuda de Vico, a linguagem "como reescrita, como história condicionada pela repetição, como codificação e disseminação" e concebe a caracterização do começo da escrita enquanto "a inauguração e subsequente manutenção de outra ordem de significado a partir de uma escrita prévia ou já existente" (SAID, 1985, p. 357; grifos do autor).

Convém sublinharmos que em Beginnings a questão colonial não aparece senão muito lateralmente. $\mathrm{O}$ debate do autor se faz não apenas em diálogo com a voga filosófica estruturalista e pós-estruturalista francesa, mas também a partir da literatura de ficção Ocidental, especialmente europeia: Joseph Conrad, James Joyce, Marcel Proust, T. S. Eliot, entre outros. É bem verdade, como notou White (1976), que o livro é, sim, político, uma vez que trata de questões como autoridade, tradição e, especialmente, poder, a categoria central também em Orientalismo. Contudo, é interessante reproduzirmos aqui parte do último parágrafo do livro:

Durante meus estudos para e na escrita deste livro, abri, acho eu, possibilidade para mim mesmo (e, espero, para outros) de exploração de outras problemáticas. Algumas delas são: a questão da linguagem como objeto de especulação, como um objeto que ocupa um lugar prioritário para o escritor; a questão formal e psicológica 
da interdependência das abordagens literária e sociológica ao lidar com o inglês, por exemplo, como língua ao mesmo tempo nacional e mundial (para alguns escritores a primeira e para outros a segunda língua); a questão mesma da literatura comparada, em tempos de campos de dispersão de temas, motivos e gêneros nos quais o começo é um passo absolutamente crucial; a questão da dominação cultural de um domínio intelectual ou nacional sobre outro (uma cultura é mais "desenvolvida" - tendo começado mais cedo ou chegado antes - do que outra); e as questões da liberdade, ou independência, ou originalidade conforme obtidas em complexas ordens de repetição social e intelectual. Esses são estudos a que eu espero que a nossa vontade moral corresponda - se em parte esse começo tiver cumprido seu propósito. (SAID, 1985, p. 380-381).

Notemos que a discussão mais direta sobre a "dominação cultural" e o jargão do desenvolvimento aparecem, aqui, como intenção de uma agenda de pesquisa da qual Beginnings faz parte, mas não se realiza no próprio livro. Apenas três anos mais tarde, em 1978, com o lançamento de Orientalismo, Said desenvolveria de forma direta o que ficou conhecido como a questão pós-colonial. ${ }^{6}$ Curiosamente, em Orientalismo o tema dos "começos" aparece apenas uma vez, logo na Introdução, e mesmo assim como uma reflexão metodológica das próprias dificuldades encontradas pelo autor para delimitar o material a ser trabalhado, por onde começar sua análise tendo em vista a enorme massa documental disponível (SAID, 1990, p. 27). No entanto, ao menos outros dois elementos já presentes em Beginnings permanecem como componentes importantes e são desdobrados em Orientalismo. O primeiro deles é o poder como chave de leitura conceitual que permite ao autor compreender os discursos europeus sobre o Oriente como uma forma de disciplina, a partir de um uso explicitamente foucaultiano. É assim que, diz Said, "podemos entender melhor a persistência e a durabilidade de sistemas

\footnotetext{
${ }^{6}$ Nesse aspecto é importante lembrarmos a entrevista que Said concede à revista Diacritics em 1976. Apesar de o mote principal ser o lançamento de Beginnings e os debates sobre teoria literária, as respostas de Said caminham para o tópico das "orientalizações do Oriente" e a relação entre a ascensão do imaginário oriental na Europa do século XIX e o colonialismo político. Trata-se, é claro, da pesquisa que resultará no livro Orientalismo.
} 
hegemônicos saturantes como a cultura quando nos damos conta de que suas coações internas sobre escritores e pensadores foram produtivas, e não unilateralmente inibidoras" (SAID, 1990, p. 26, grifo do autor). Tratase de uma compreensão positiva sobre o poder, visto como produtor de uma eficiência, de uma aptidão e, por outro lado, que percebe como os mecanismos de poder são técnicas e procedimentos que foram inventados e aperfeiçoados. No entanto, e aqui chegamos à segunda aproximação com Beginnings, Said procura se afastar dos estruturalistas (incluindo Foucault, e especialmente sua discussão sobre a noção de Autor) ao conferir um grau maior de agência aos escritores, ou, como escreve, "acredito que existe uma marca determinante dos escritores individuais sobre o que de outro modo seria um anônimo corpo coletivo de textos que constituem uma formação discursiva como o orientalismo" (SAID, 1990, p. 34).

Apesar de em Beginnings Said operar uma desconstrução da ideia de origem, curiosamente em seu livro mais importante no debate póscolonial, Orientalismo, como observa Homi K. Bhabha, ele recai numa visão dualista e demasiado unilateral da relação colonial. Para Bhabha, o discurso colonial - e o orientalismo é uma de suas variantes - consistiria em um aparato de poder que produz o reconhecimento e a negação de diferenças por meio de conhecimentos que permitem exercer a vigilância dos "povos sujeitos". "Apesar do jogo de poder no interior do discurso colonial e das posicionalidades deslizantes de seus sujeitos (por exemplo, efeitos de classe, gênero, ideologia, formações sociais diferentes, sistemas diversos de colonização, e assim por diante)", argumenta Bhabha, tratase de um "forma de governamentalidade que, ao delimitar uma "nação sujeita', apropria, dirige e domina suas várias esferas de atividade" e que "produz o colonizado como uma realidade social que é ao mesmo tempo um 'outro' e ainda assim inteiramente apreensível e visível" (BHABHA, 2010, p. 111). A legitimação dessa estratégia envolve a criação de estereótipos do colonizador e do colonizado que corroborem a superioridade e autoridade do primeiro.

Bhabha (2010, p. 112), porém, chama atenção para a polaridade que atravessa o orientalismo, notada apenas de passagem por Said: “este é, por um lado, um tópico de aprendizado, descoberta, prática; por outro lado, é território de sonhos, imagens, fantasias, mitos, obsessões e requisitos". O orientalismo é uma disciplina - um corpo de saber enciclopédico e poder imperial (que Said denomina orientalismo manifesto) - mas também 
uma "uma positividade inconsciente" de fantasia do Outro (orientalismo latente). Embora reconheça a originalidade e o pioneirismo da formulação de Said, Bhabha (2010, p. 112) pondera que ela permanece presa a um binarismo, deixando de fora a alteridade e a ambivalência do discurso orientalista: "estabelecendo inicialmente uma oposição entre essas duas cenas discursivas, finalmente lhes permite a correlação como sistema congruente de representação que é unificado através de uma intenção político-ideológica que, em suas palavras, possibilita à Europa avançar segura e não-metaforicamente sobre o Oriente."

À diferença de outros críticos, que acusam Said de ter pintado uma imagem demasiado hegemônica do discurso orientalista, Bhabha mostra como para o próprio Said esse discurso encerra ambivalências. $\mathrm{O}$ problema, no entanto, estaria no fato de que Said as "resolve" ao reduzilas à "intenção" originária de possessão imperial europeia sobre o Oriente, como se o poder colonial fosse possuído inteiramente pelo colonizador e o colonizado destituído de agência, e a esse desígnio unidirecional correspondesse um discurso orientalista igualmente monolítico. Ao incorrer nessa oposição binária e simplificadora entre poder/falta de poder que acentua a dominação, sua perspectiva não abre espaço para a negociação e a resistência e acaba perdendo de vista que o poder colonial está sujeito a conflitos. Assim, Bhabha procura aprofundar a ideia de que o orientalismo, enquanto representação, forma um discurso - e, portanto, implica lugares de enunciação, de modo que

um repertório de posições conflituosas constitui o sujeito no discurso colonial. A tomada de qualquer posição, dentro de uma forma discursiva específica, em uma conjuntura histórica particular, é portanto sempre problemática lugar tanto da fixidez como da fantasia. Esta tomada de posição fornece uma 'identidade' colonial que é encenada - como todas as fantasias de originalidade e origem diante de e no espaço da ruptura e da ameaça por parte da heterogeneidade de outras posições. (BHABHA, 2010, p. 120).

Bhabha argumenta, assim, que, mesmo para o colonizador, a construção da representação do outro é mediada, ambivalente e contraditória, como demonstra sua análise do estereótipo. 
Julgar a imagem estereotipada com base em uma normatividade política prévia é descartá-la, não deslocála, o que só é possível ao se lidar com a sua eficácia, com o repertório de poder e resistência, dominação e dependência, que constrói o sujeito da identificação colonial (tanto colonizador como colonizado). [...] Só então torna-se possível compreender a ambivalência produtiva do objeto do discurso colonial - aquela "alteridade" que é ao mesmo tempo um objeto de desejo e escárnio, uma articulação da diferença contida dentro da fantasia da origem e da identidade. $\mathrm{O}$ que essa leitura revela são as fronteiras do discurso colonial, permitindo uma transgressão desses limites a partir do espaço daquela alteridade. (BHABHA, 2010, p. 106, grifo do autor).

Nos seus primeiros trabalhos de crítica literária - debruçandose sobre autores coloniais ingleses, como Forster, Conrad e Kipling -, Bhabha estava interessado justamente no confronto de representações (metropolitanas e "nativas") do sujeito colonial. Adotando uma perspectiva desconstrutivista que valorizava o hibridismo constitutivo da linguagem e das identidades (e, portanto, também das representações), Bhabha descarta o esquema binarista que inseria o sujeito colonizado num gradiente de autenticidade, como se tudo se resumisse a meramente substituir imagens distorcidas (produzidas pelos colonizadores) sobre eles por outras corrigidas, porque reflexos mais fiéis de uma pressuposta "realidade" extratextual fixa - espécie de origem ou essência do referente, anterior à própria narração, à própria performatização da representação. Essa visão estaria enraizada no que ele chama de "conluio entre o historicismo e o realismo", de acordo com o qual o tempo é linear, evolutivo e progressivo, e a realidade, uma totalidade coerente e ordenada; bem como ambos são passíveis de apreensão direta. Numa representação desse tipo, o signo é considerado unitário e dado (posto que não construído) e não há, portanto, intervalo entre o significante e o significado. A linguagem perde assim sua dimensão social e histórica. Para Bhabha, porém, o discurso não é representação não mediada de uma realidade transcendental (mimese), mas um processo produtivo de significados construídos num jogo de diferenças, referências e conflitos (que não se resolvem), a partir de várias posições de sujeitos ideológica e historicamente situados. 
O que ele chama de hibridismo se torna visível justamente no deslocamento entre o significante e o significado, cuja mediação é feita por intérpretes localizados em determinados contextos ideológicos, históricos e sociais e atravessados de marcadores sociais de diferença (daí a importância da ideia de lugar de enunciação). É na interação de elementos linguísticos e culturais nesse espaço intersticial ou "Terceiro Espaço", como ele o denomina, que se constitui o hibridismo. Ele configura um problema não de genealogia ou identidade, mas de representação, capaz de reverter os efeitos discriminatórios do poder colonialista ao permitir a penetração dos saberes "negados" ou silenciados no discurso dominante e o seu estranhamento por dentro das regras de reconhecimento da alteridade que sustentam sua autoridade. Assim, as diferenças não são decorrências de uma identidade ontológica transcendente; trata-se de um problema de natureza performática:

a regulação e a negociação daqueles espaços que estão continuamente, contingencialmente, se abrindo, retraçando as fronteiras, expondo os limites de qualquer alegação de um signo singular ou autônomo de diferença - seja ele classe, gênero ou raça. (BHABHA, 2010, p. 301, grifo do autor).

O hibridismo é o signo da produtividade do poder colonial, suas forças e fixações deslizantes; é o nome da reversão estratégica do processo de dominação pela recusa (ou seja, a produção de identidades discriminatórias que asseguram a identidade "pura" e original da autoridade). O hibridismo é a reavaliação do pressuposto da identidade colonial pela repetição de efeitos de identidade discriminatórios. Ele expõe a deformação e o deslocamento inerentes a todos os espaços de discriminação e dominação. Ele desestabiliza as demandas miméticas ou narcísicas do poder colonial, mas confere novas implicações a suas identificações em estratégias de subversão que fazem o olhar do discriminado voltar-se para o olho do poder. [...] Se os efeitos discriminatórios permitem às autoridades vigiá-los, sua diferença que prolifera escapa àquele olho, escapa àquela vigilância. Aqueles contra os quais se discrimina podem ser instantaneamente reconhecidos, mas eles também forçam um re-conhecimento da imediação e da articulação da autoridade - um efeito perturbador 
que é costumeiro na hesitação repetida que aflige o discurso colonialista quando ele contempla seus sujeitos discriminados: a inescrutabilidade dos chineses, os ritos inenarráveis dos indianos, os hábitos indescritiveis dos hotentotes. Não é que a voz da autoridade fique sem palavras. Na verdade, é o discurso colonial que chegou àquele ponto em que, face a face com o hibridismo de seus objetos, a presença do poder é revelada como algo diferente do que o que suas regras de reconhecimento afirmam. (BHABHA, 2010, p. 162-163, grifos do autor).

A própria ideia de cultura seria, assim, descentrada pelas experiências pós-coloniais de deslocamento compreendidas tanto pela escravização quanto pelas diásporas migratórias das metrópoles para as colônias e vice-versa. A partir da ideia de Terceiro Espaço, Bhabha se propõe a ressignificar o conceito substantivo de cultura - que considera uma totalidade estática, homogênea e essencializada - como "ato tradutório", estratégia performática de identificação diferencial: híbrida, produtiva, dinâmica, aberta e inacabada. Nessa concepção, as culturas seriam transnacionais e desterritorializadas, uma vez que carregariam as marcas e memórias desses deslocamentos, e implicariam tradução, já que os símbolos culturais tradicionais - que acentuariam os particularismos a partir das ideias unificantes de "povo" e "nação" - seriam ressignificados como signos passíveis de interpretações diferentes, dada a multiplicidade de contextos e sistemas de valores que se justapõem e entram em conflito na constituição híbrida das culturas pós-coloniais. A tradução revelaria o hibridismo das culturas, constituída pela diferença e pelas alteridades e, logo, a heterogeneidade das suas "origens". Esses "atos tradutórios" têm importância, pois, segundo Bhabha (2010), permitem que as histórias subalternas, frequentemente reprimidas, se escrevam nas "entrelinhas" das práticas culturais hegemônicas - que se arrogam supremacia, soberania, autonomia e hierarquia -, explicitando o hibridismo tanto da cultura dominante quanto das culturas "nativas".

\section{Silviano, autor de The location of culture?}

O foco na ambivalência da relação colonial parece representar o passo adiante dado por Bhabha em sua leitura crítica de Said, formalizado a partir das ideias de "interstício", "terceiro espaço" e hibridismo. No 
entanto, como já enunciado no início de nossa argumentação, essa preocupação já se mostrava decisiva na qualificação do conceito de "entre-lugar" desenvolvido contemporaneamente a Said por Silviano Santiago, como veremos agora.

Uma literatura nos trópicos é livro intempestivo e feroz, de combate - que fala contra, escreve contra, e que não por acaso se inicia com uma cena bélica. Feroz porque não se deixa domesticar por rótulos como pós-colonial, decolonial e afins, embora os antecipe. E, portanto, também livro seminal porque abre pioneiramente (muito antes de se tornar "modismo" ou grife, note-se) uma agenda de pesquisas sobre a dependência das culturas subalternas e de crítica ao eurocentrismo que, não fosse a força desse próprio discurso e a geopolítica do conhecimento a que ele dá lastro, seria cultuado nos principais centros acadêmicos internacionais. Além do mais, o livro rompe precocemente com o nacionalismo metodológico que vinha caracterizando as ciências sociais e as humanidades em geral ${ }^{7}$ - gesto esse radicalizado com a temática mais recente do cosmopolitismo do pobre (SANTIAGO, 2004) - e afirma a especificidade da periferia - apesar de dependente, universal - enquanto lugar de enunciação sobre o mundo em que o conflito e a diferença emergem.

A questão das origens é fundamental no livro, que evocava o debate quase obsessivo para a intelectualidade do Novo Mundo sobre a dependência cultural da colônia em relação à metrópole - como, aliás, indica seu subtítulo, "Ensaios sobre dependência cultural". Como observa Eneida Cunha (2018), já as epígrafes do primeiro ensaio - "O entre-lugar do discurso latino-americano" - delineiam a articulação que será central no seu argumento. Uma delas é uma citação de Quarup, de Antonio Callado, e faz menção à argúcia do frágil jabuti abocanhado pela onça, dois animais característicos do folclore nativo: "Do crânio da onça o jabuti fez seu escudo"; a outra é uma recomendação de Michel Foucault para as "tarefas negativas" de desconstrução do saber baseado na semelhança: "É preciso se libertar de todo um jogo de noções que estão ligadas ao postulado de continuidade" (FOUCAULT apud SANTIAGO, 2000, p. 9). Notemos como Silviano já pensa e operacionaliza a contribuição da

\footnotetext{
${ }^{7}$ Sobre o debate recente a respeito desse tema nas ciências sociais, ver a proposta de Beck (2006) de uma "sociologia cosmopolita" e a crítica de Bhambra (2014).
} 
teoria francesa "pós-estruturalista" filtrada pelo repertório de ideias e símbolos latino-americanos.

"A maior contribuição da América Latina para a cultura ocidental vem da destruição sistemática dos conceitos de unidade e pureza" (SANTIAGO, 2000, p. 16; grifos do autor). O ensaio é uma espécie de "protótipo do gesto pós-colonial" (CUNHA, 2018) e se insurge contra o silenciamento etnocêntrico da alteridade e da diferença das culturas que se defrontaram com a violência do processo colonial e expansionista europeu no repertório das ciências sociais e humanas e nas histórias literárias e culturais do Brasil. Silviano

expõe o incessante retorno dessa violência recalcada nas hierarquias entre civilização e barbárie, Europa e Novo Mundo, que se desdobram em outras infindáveis e assimétricas oposições, entre centro e periferia, tradição erudita e cultura popular ou massiva, estética e política. $\mathrm{O}$ alvo é a polarização entre vontade de pureza e vivência da mestiçagem, entre colonização (a imposição do modelo às cópias) e descolonização (a agressividade desviante dos simulacros). Com a contundência própria daqueles tempos de opressão política e agitação cultural, a análise de Silviano descarta a (esperada) síntese dialética e propõe a reversão das classificações, o valor do híbrido, dos paradoxos e contradições. (CUNHA, 2018).

Em "O entre-lugar do discurso latino americano", é necessário - e é disso que se trata, afinal, de uma necessidade - que tenhamos clareza dos desafios e possibilidades inerentes à reflexão nos trópicos, ou desde o Sul, como alguns prefeririam dizer hoje. Escrito em um contexto não apenas de ditadura militar, mas também de apreensão pelas novas formas de colonialismo, o ensaio sobre dependência cultural de Silviano abre com a imagem famosa e bélica do capítulo de Montaigne sobre os canibais, em que o rei Pirro se surpreende com a organização do exército romano, que lhe parecia bem menos bárbaro do que deveria, ao menos segundo o conceito geral dos povos civilizados daquele tempo. O campo de batalha retratado por Montaigne, que coloca frente a frente bárbaros e civilizados, e a surpresa do líder grego capturam um deslocamento sutil, mas potencialmente decisivo. Bem ajustada, a metáfora pode ser pensada para outros quadrantes e outras dinâmicas coloniais. 
Falar em um “entre-lugar” implica, é preciso deixar claro, pensar um lugar concreto e específico, e não um mero lugar de passagem, ou um "não lugar" à la Marc Augé (1994). O que confere densidade histórica e geográfica a ele é o empreendimento colonial, construído sob o signo da homogeneidade e pelo apagamento sistemático da diferença, afinal, "na álgebra do conquistador a unidade é a única medida que conta" (SANTIAGO, 2000, p. 16). Se o extermínio físico é a regra, há outro mais sutil, ainda que não menos eficaz, implicado no controle sobre a língua e sobre os sistemas do sagrado, que ordena que se evite a todo custo práticas como o bilinguismo e o pluralismo religioso, ao mesmo tempo em que impõe ao "bárbaro" os "altos padrões" da civilização ocidental. Adestrado qualquer laivo de singularidade, só resta à América "transformar-se em cópia, simulacro que se quer mais e mais semelhante ao original" (SANTIAGO, 2000, p. 16). A dominação colonial, no entanto, engendra um segundo processo, paralelo ao primeiro, só que mais silencioso e em caminho oposto: o "novo mundo nos trópicos" é também o da miscigenação racial, o da contaminação da pureza, o da corrupção dos códigos linguísticos e religiosos. Tais códigos, mostra Silviano, "perdem seu estatuto de pureza e pouco a pouco se deixam enriquecer por novas aquisições, por miúdas metamorfoses, por estranhas corrupções, que transformam a integridade do Livro Santo e do Dicionário e da Gramática europeus. O elemento híbrido reina" (SANTIAGO, 2000, p. 18). Se o colonialismo procurava a todo custo erradicar as diferenças, sua própria dinâmica fez com que novas relações, imagens e sons aparecessem, pouco identificáveis aos ouvidos talvez insensíveis do colonizador.

Mas se o entre-lugar está referido a um processo histórico específico, ele também deve ser entendido como um lugar a partir do qual se fala, e não apenas sobre o qual se pode dizer algo. Caberia ao intelectual latino-americano, antes de tudo, compreender esse lugar e saber usá-lo, transformar o entre-lugar em um espaço eminentemente analítico para ver o mundo e se relacionar com ele a partir de uma perspectiva própria. Assim como posteriormente Bhabha qualificaria o Terceiro Espaço, o "entre-lugar" se constitui precisamente como aquele local onde as "condições discursivas da enunciação" (BHABHA, 1998, p. 68) permitem que se perceba com mais nitidez como pretensões de "unidade" e "autenticidade" são falsas em qualquer dinâmica cultural. As culturas (e as identidades) são, não unidades expressivas e homogêneas, campo do consenso e da reconciliação, mas sempre abstrações da história 
das misturas em que se formaram e dos conflitos que as construíram. No entanto, Silviano também está atento ao fato de que os permanentes fluxos e trocas que as constituem não acarretam integração ou fusão harmoniosa, mas contradições e, sobretudo, assimetria. Economia política e cultura articulam-se - não é como se as desigualdades socioeconômicas fossem não simbólicas ou as diferenças culturais fossem imateriais ou apolíticas (ver, a propósito, Hoelz (2018) sobre a proximidade dessa abordagem com a de Mário de Andrade).

Portanto, se a importação cultural produz distorções significativas para as sociedades dependentes, a cópia é inevitável, e é justamente no deslocamento provocado por ela, na repetição com diferença - e na reelaboração suscitada pelas contradições locais do processo histórico - que se deixa ver o entre-lugar das culturas periféricas e subalternas. Daí Silviano Santiago, ao se debruçar sobre uma parcela da tradição dos estudos literários no Brasil, questionar a tendência recorrente de pesquisa das "fontes" ou das "influências", que, segundo ele, apenas reproduziriam o discurso neocolonialista e policialesco das origens, e, portanto, da pureza capaz de iluminar todo o resto. Ao contrário, o que lhe interessa são os deslocamentos, os tensionamentos das visões estáveis e polarizadas de identidade, as múltiplas variações de significado a partir de um mesmo e aparente cristalizado significante. E assim o é porque o escritor e o intelectual em contextos pós-coloniais situam-se nesse espaço complexo, entre a assimilação a um suposto modelo original e a necessidade constante e incansável (e talvez inalcançável) de reescritura. Assim, a posição quase marginal leva a uma perspectiva entre as fronteiras e, por isso, contingente e refratária a ontologias e essencialismos. A propósito, como observa Botelho (2019), o conceito de entre-lugar implica uma ideia potente de "movimento" e de relação - carregada de conflito e de poder, mas também potencialmente de solidariedade - que aproxima e separa diferenças. Além de usar o termo algumas vezes, há várias outras expressões no texto que ressoam essa ideia de movimento: "infiltração progressiva" do pensamento selvagem no elemento europeu; movimento de "sabotagem dos valores culturais e sociais impostos pelos conquistadores"; "miúdas metamorfoses" que enriquecem pouco a pouco os códigos linguístico e religioso; "transfiguração" que institui o lugar da América Latina no mapa da civilização ocidental; "meditação traiçoeira", "tradução" e "aprendizagem" envolvidas na repetição diferida da língua e do texto primeiro da metrópole (SANTIAGO, 2000). 
Isso posto, se, anteriormente, o conceito de originalidade havia servido para dar prioridade à Europa sobre a cópia degradada que dela sempre seria a América Latina, o seu questionamento permite a Silviano avançar na direção de uma noção na qual a repetição instaura uma diferença que repercute inclusive sobre o contexto original, corrompendo a sua presumida originalidade. Eis o pulo do gato. Não se trata simplesmente de realizar uma operação de inversão, em que se passa a valorizar a cópia. Não. A cópia, como reflexo de um original determinado, evidencia elementos que não apareciam nele, fazendo dessa primeira instância algo dependente, para sua atualização, da própria cópia. É tão somente na cópia que o original se torna evidente como tal, o que significa dizer que o original não existe na ausência da cópia.

O conceito de suplemento, emprestado de Derrida, joga papel central aí. Em seu ensaio "Eça, autor de Madame Bovary", Silviano mobiliza esse conceito para reler, a partir de "Pierre Menard, autor del Quijote" de Jorge Luis Borges, a familiaridade do Primo Basílio com o romance de Flaubert. Apesar de a geração de Eça em Portugal ser dependente da cultura francesa, o suplemento da leitura - isto é, o que se acresce ao original e o diferencia dele - torna a "cópia", paradoxalmente, mais original do que o "modelo", uma vez que ela contém em si ao mesmo tempo "uma representação do texto dominante e uma resposta a esta representação no próprio nível da fabulação" (SANTIAGO, 1982, p. 23), como esclarece no ensaio emblematicamente intitulado "Apesar de dependente, universal". O texto segundo repete e cita em si mesmo o texto primeiro como arquivo de leitura - ele incorpora o primeiro mais a sua leitura - e, assim, explicita nele a sua condição de texto escrito a partir de outros textos (do "já-escrito", como Silviano adapta o "déjàdit" de Foucault), que é a de todos os textos, como nota Penna (2012). Desse modo, a cópia diferida do modelo poderia engendrar um produto original. Mas originalidade, está claro, não equivale à pureza e/ou à autenticidade; ao contrário, envolve o relacionamento com a diferença. Dessa perspectiva desprovincianizante e não triunfalista que recusa a dualidade sem, porém, buscar transcendê-la ou superá-la numa síntese decorre uma ideia de que as identidades não seriam inteiriças e fechadas em si mesmas, mas dinâmicas, abertas e relacionais.

A vacina contra o eurocentrismo, a "moléstia de Nabuco" de que falava Mário de Andrade e será retomada por Silviano - essa doença tropical transmitida aos jovens pelo bacilo das ninfas europeias 
- consistiria, assim, em rechaçar a idealização e o recalque do passado nacional, para adotar como estratégia estética e economia política a inversão dos valores hierárquicos estabelecidos pelo cânone eurocêntrico. Essa estética política, necessariamente periférica, ambivalente e precária, compreende tanto o desrecalque localista da multiplicidade étnica e cultural das práticas populares abominadas pela elite quanto o nexo da nossa formação nacional com o pensamento universal não eurocêntrico. Atentando para o localismo do universal e o alcance universalista do local - isto é, sem reificar nem localismos em seu particularismo nem o universalismo em sua abstração -, Silviano vira do avesso a perspectiva colonial. Não se trata, portanto, de substituir um discurso eurocêntrico por outro igualmente autocentrado e totalizante, mas de desenvolver um modo descentrado de relação de convivência com o universal a partir da diferença local, que implica movimento e abertura em várias direções e, neste gesto, uma concepção plural e cosmopolita de civilização. Diz Silviano:

Não fui vítima da lucidez racional da Europa como um novo Joaquim Nabuco, nem me deixei seduzir pelo espocar dos fogos de artifício ou pelas cores do carnaval nos trópicos. Fiquei com os dois e com a condição de viver e pensar os dois. Paradoxalmente. Nem o lugarcomum dos nacionalismos brabos, nem o lugar-fetiche do aristocrata saber europeu. Lugar-comum e lugar-fetiche imaginei o entre-lugar e a solidariedade latino-americana. (SANTIAGO, 2001, p. 434).

\section{Considerações finais}

Como esperamos ter mostrado, um dos ganhos teóricos obtidos pelo conceito de "entre-lugar", para além da desconstrução das ideias de origem, unidade e pureza, é o de evitar narrativas que reponham a dualidade identificada por Stuart Hall na fórmula West/Rest, atentando para a complexidade e ambiguidade da relação colonial. Isso é especialmente rico no caso do "discurso latino-americano" porque uma série de perspectivas anteriores e posteriores apontaram para essas zonas de incerteza e impureza que desestabilizam as grandes linhagens teleológicas, apostando em instâncias históricas heterogêneas, capazes de desmontar a possibilidade de um discurso enunciador totalizante, 
homogêneo e arbitrariamente hierarquizador. Pensamos, por exemplo, em noções como antropofagia (Oswald de Andrade), transculturação (Ortiz, Rama), brega (Díaz-Quiñones), pensamento de fronteira ("border thinking"; Mignolo), zonas de contato (Pratt), mestiçagem (Gruzinski), entre outras.

Desconstruir o eurocentrismo, como vimos, também não implica em rejeitar ou descartar o pensamento europeu, posto que ele é a um só tempo indispensável e inadequado (CHAKRABARTY, 2000) para nos ajudar a entender as experiências da modernidade em países não ocidentais e periféricos. Envolve explorar o modo pelo qual esse pensamento - que agora é herança comum e afeta todos nós - pode ser renovado a partir de e para as margens. É claro, as margens são tão plurais e diversas quanto os centros. Nesse sentido, a Europa aparece diferente quando vista a partir de experiências de colonização de distintas partes do mundo. $\mathrm{O}$ intelectual pós-colonial, falando a partir de suas diferentes geografias de colonialismo, fala de diferentes Europas. Porém, não importa quão múltiplos sejam os loci da Europa e quão variáveis os colonialismos, o problema de ir além das histórias eurocêntricas permanece uma preocupação compartilhada que cruza as fronteiras geográficas.

\section{Referências}

AUGÉ, Marc. Não lugares: introdução a uma antropologia da supermodernidade. Campinas: Editora Papirus, 1994.

BECK, Ulrich. Cosmopolitan Vision. Cambridge: Polity Press, 2006.

BHABHA, Homi K. O local da cultura. Belo Horizonte: Editora UFMG, 2010.

BHAMBRA, Gurminder K. Connected Sociologies. London: Bloomsbury, 2014.

BOTELHO, André. Sinal dos tempos: anacronismo e atualidade de Uma literatura nos trópicos. In: SANTIAGO, Silviano. Uma literatura nos trópicos. Recife: Cepe, 2019.

CHAKRABARTY, Dipesh. Provincializing Europe: postcolonial thought and historical difference. Princeton: Princeton University Press, 2000. 
CUNHA, Eneida L. "Uma literatura nos trópicos" e a urgência de "escrever contra". Pernambuco: Suplemento Cultural do Diário Oficial do Estado de Pernambuco, Recife, 08 maio 2018. Disponível em: http:// www.suplementopernambuco.com.br/artigos/2085-uma-literatura-nos-

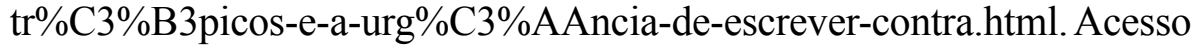
em: 23 jan. 2020.

DONATO, Eugenio; MACKSEY, Richard. The Structuralist Controversy. Baltimore: The Johns Hopkins University Press, 1972.

HOELZ, Maurício. O espelho de Macunaíma: o Ensaio sobre música brasileira para além do nacionalismo. Sociol. Antropol., Rio de Janeiro, v. 8, n. 2, p. 599-627, ago. 2018. DOI: http://dx.doi.org/10.1590/223838752017v8210. Disponível em: http://www.scielo.br/scielo. php?script=sci_arttext\&pid=S2238-38752018000200599\&lng=en\&nr $\mathrm{m}=$ iso. Acesso em: 23 jan. 2020.

MAIA, João M. E. Ao sul da teoria: a atualidade teórica do pensamento social brasileiro. Sociedade e Estado, Brasília, v. 26, n. 2, p. 71-94, ago. 2011. DOI: https://doi.org/10.1590/S0102-69922011000200005

NIETZSCHE, Friedrich. Genealogia da moral. Tradução de Paulo César de Souza. São Paulo: Companhia das Letras, 1998.

PENNA, João Camillo. Formações do sujeito colonial: suplemento, dependência, cosmopolitismo. Alea, Rio de Janeiro, v. 14, n. 2, p. 295-306, dez. 2012. DOI: http://dx.doi.org/10.1590/S1517106X2012000200010. Disponível em http://www.scielo.br/scielo. php?script=sci_arttext\&pid=S1517-106X2012000200010\&lng=pt\&nr $\mathrm{m}=$ iso. Acesso em: 23 jan. 2020.

SAID, Edward W. Interview: Edward W. Said. Diacritics, [S.l.], v. 6, n. 3, p. 30-47, 1976. DOI: https://doi.org/10.2307/464828

SAID, Edward. Beginnings: Intention and Method. Nova York: Columbia University Press, 1985.

SAID, Edward. Orientalismo. São Paulo: Companhia das Letras, 1990.

SANTIAGO, Silviano. Apesar de dependente, universal. In: .Vale quanto pesa. Rio de Janeiro: Paz e Terra, 1982. 
SANTIAGO, Silviano. Borges. In: SCHWARTZ, Jorge. Borges no Brasil. São Paulo: Editora UNESP, 2001.

SANTIAGO, Silviano. O cosmopolitismo do pobre: crítica literária e crítica cultural. Belo Horizonte: Editora UFMG, 2004.

SANTIAGO, Silviano. O entre-lugar do discurso latino-americano. In: SANTIAGO, Silviano. Uma literatura nos trópicos: ensaios sobre dependência cultural. São Paulo: Perspectiva: Secretaria da Cultura, Ciência e Tecnologia do Estado de São Paulo, 2000.

WHITE, Hayden. Criticism as Cultural Politics. Diacritics, v. 6, n. 3, p. 8-13, 1976. DOI: https://doi.org/10.2307/464825. 